\title{
Monitoring of anti-TNF biological treatments
}

\author{
A Ruiz del Agua ${ }^{1}$, D Pascual-Salcedo², A Balsa ${ }^{3}$, I Ramos ${ }^{1}$, L Novalbos$^{1}$, S Ramiro², A Martínez ${ }^{1}$, \\ L Simón ${ }^{1}$, D Nagore ${ }^{1 *}$ \\ From 5th European Workshop on Immune-Mediated Inflammatory Diseases \\ Sitges-Barcelona, Spain. 1-3 December 2010
}

\section{Introduction}

Many therapeutic proteins, especially chimeric and humanized anti-TNFalpha antibodies, produce an unwanted immune response that can cause secondary failure and infusion reactions [1]. The most widely accepted hypothesis is the neutralization of the therapeutic agents by human anti-drug antibodies (ADA) [2].

\section{Aim}

An ambispective observational study was conducted to determine the correlation between drug bioavailability, immunogenicity, and loss of clinical efficacy in rheumatoid arthritis (RA) patients treated with infliximab and adalimumab.

\section{Patients and methods}

Informed consents were obtained from all patients. Serum samples were collected from 78 and 51 patients at baseline and during the course of treatment over a year with infliximab and adalimumab, respectively. Concentrations of ADAs and free drugs were measured with Promonitor ${ }^{\circ}$ test. Progression of the disease was evaluated using Disease Activity Score (DAS28) index. European League Against Rheumatism (EULAR) response criteria were used to assess clinical response, and the population was classified at the end of the treatment year into responder patients $(\triangle \mathrm{DAS} 28 \geq 1.2)$ and non-responder patients $(\triangle \mathrm{DAS} 28<1.2)$.

\section{Results}

$47 \%$ and $20 \%$ of the patients developed antibodies against infliximab and adalimumab, respectively. For both treatments there is a strong inverse association between the concentration of circulating drug and the presence of antibodies $(p<-0.001)$. The concentration of circulating drug inversely correlates with DAS28 $(p<-0.001)$. There

${ }^{1}$ Proteomika, S.L, Derio, Spain

Full list of author information is available at the end of the article is also a direct correlation between the presence of ADAs and the evolution of the disease measured through DAS28. ADA concentrations were significantly higher in non-responders compared to responder patients.

\section{Conclusion}

Regular monitoring of ADAs and circulating drug helps to optimize the efficacy of biologicals, to improve patient management and make a rational use of these expensive therapies.

\section{Author details}

${ }^{1}$ Proteomika, S.L, Derio, Spain. ${ }^{2}$ Servicio de Inmunología, Hospital Universitario La Paz, Madrid, Spain. ${ }^{3}$ Servicio de Reumatología, Hospital Universitario La Paz, Madrid, Spain.

Published: 25 November 2010

\section{References}

1. Wolbink GJ, Aarden LA, Dijkmans BA: . Curr.Opin.Rheumatol 2009, 21:211-215.

2. Radstake TR, Svenson M, Eijsbouts AM, van den Hoogen FH, Enevold C, van Riel PL, Bendtzen K: . Ann.Rheum.Dis. 2008, 68:1739-1745.

doi:10.1186/1479-5876-8-S1-P32

Cite this article as: Ruiz del Agua et al:: Monitoring of anti-TNF biological treatments. Journal of Translational Medicine 2010 8(Suppl 1):P32. 